\title{
Distribution of sagittal occlusal relationships in different stages of dentition
}

Emine KAYGISIZ ${ }^{(a)}$

Lale TANER(a)

Kahraman GUNGOR ${ }^{(\text {b) }}$

(a)Gazi University, Dental Faculty, Department of Orthodontics, Ankara, Turkey.

(b)Gazi University, Dental Faculty, Department of Oral and Dentomaxillofacial Radiology, Ankara, Turkey.
Declaration of Interests: The authors certify that they have no commercial or associative interest that represents a conflict of interest in connection with the manuscript.

Corresponding Author:

Emine Kaygısız

E-mail:dt.emineulug@mynet.com

DOI: 10.1590/1807-3107BOR-2015.vol29.0007

Submitted: Mar 31, 2014

Accepted for publication: Aug 13, 2014

Last revision: Oct 09, 2014

\begin{abstract}
The aim of this study was to assess the distribution of sagittal occlusal relationships in different dentition periods in a Turkish sample group. In total, 1,110 patients (561 females, 549 males) aged 4.6-23 years were randomly chosen after intraoral clinical examination. The subjects were classified according to their sagittal occlusal relationships and four dentition stages -deciduous, early mixed, late mixed, and permanent dentition. The statistical significance of the occurrence of malocclusion types in dentition stages was evaluated by Chi-square and Fischer's exact tests. Class I malocclusion was observed at the highest rate in all dentition stages. Class III malocclusion was observed at the highest rate in the permanent dentition, whereas Class II malocclusion was observed at the highest rate in the late mixed dentition. The rates of Class I, II, and III malocclusions were similar in males and females. Our study reveals that the prevalence of malocclusion and need for orthodontic treatment has increased in the population towards the permanent dentition.
\end{abstract}

Keywords: Dentition; Orthodontics; Malocclusion; Prevalence.

\section{Introduction}

Epidemiological data on the prevalence of malocclusions is valuable for understanding the etiologies of orthodontic discrepancies. Such data also provides information about the demand for orthodontic treatment, the availability of orthodontic clinics, ${ }^{1}$ and the distribution of malocclusions in different populations. . $3,3,5,6 \mathrm{~A}$ number of studies have addressed the prevalence of malocclusions in different populations. ${ }^{3,6,7,8}$ Mugonzibwa et al. ${ }^{6}$ reported that Tanzanian children are more likely to have a Class I occlusion than Finnish children, Asians have the lowest frequency of Class II malocclusions, and eastern European and Asian subjects have the highest frequency of Class III malocclusions. ${ }^{3}$ The prevalence of Class III malocclusions is reported to be $4.2 \%$ in Australian Caucasian adults ${ }^{7}$ and $49.1 \%$ in Chinese subjects. ${ }^{8}$ Yang $^{8}$ showed that the percentage of Class III malocclusions increased whereas Class I malocclusions decreased in patients examined over a 5-year period who had been referred to the Department of Orthodontics. Because the Angle's classification system minimizes subjectivity, ${ }^{9}$ these variations in the prevalence of malocclusions observed in these different studies ${ }^{3,6,7,8}$ may be due to different sample sizes among studies or to different ethnic origins, ages, and dentition stages of the patients. 
No studies have reported the rates of sagittal occlusal relationships in different dentition stages in the Turkish population. Therefore, we assessed the distribution of sagittal occlusal relationships in different dentition periods in a Turkish sample group.

\section{Methodology}

This study was approved by the Ethics Committee of Ankara University Dental Faculty (36290600/62). All patients/parents were informed of the purpose of the study, and their written consent was given prior to entering the study. Subjects $(3,452)$ who were admitted to the Oral and Dentomaxillofacial Radiology Department of Dental Faculty, Gazi University were randomly selected for initial intraoral clinical examination in conjunction with their routine dental health evaluation and treatment. Intraoral inspection data were assessed retrospectively for determination of prevalence of malocclusion in the 3,452 subjects. Edentulous and partially edentulous subjects, patients who had undergone previous orthodontic treatment, subjects with craniofacial anomalies, and non-Turkish nationals were excluded from further analysis. The data for the remaining 1,110 subjects (561 females, 549 males) aged 4.6-23 years were evaluated to determine the prevalence of malocclusion. The examined subjects reflect the broader Turkish population because Ankara is the capital city, located in the central part of Turkey, where individuals from every province of Turkey come to receive health care.

The subjects were categorized according to four dentition stages (deciduous, early mixed, late mixed, and permanent) rather than chronological age to eliminate individual variation in development. The early mixed dentition stage begins with incisor emergence on the maxilla or mandible, the late mixed dentition stage begins with replacement of the first primary molars with permanent premolars, and the permanent dentition stage starts with emergence of second permanent premolars and completion of exfoliation of all deciduous teeth. The second and third molars were not considered.

Malocclusions were defined according to Angle's classification system ${ }^{10}$ as Class I, II, or III in the permanent dentition. For primary dentition, the normal relationship is a flush terminal plane. When the first permanent molars erupt, their relationship is determined by that of the primary molars. The molar relationship tends to shift at the time the second primary molars are lost and the adolescent growth spurt occurs. The amount of differential mandibular growth and molar shift into the Leeway space determines the molar relationship. Forward growth of the mandible or a shift of teeth can cause the mesial step to develop into Class III malocclusion, ${ }^{11}$ whereas the distal step in the deciduous dentition can develop into a Class II molar relationship. ${ }^{12}$

In this study, subjects having a flush terminal plane, Class I deciduous canine relationship, minimal variation in overbite, and overjet in the deciduous, early mixed and late mixed dentition stages were considered Class I; subjects having the concomitant presence of distal step, Class II deciduous canine relationship, and excessive overjet were considered Class II; subjects having the concomitant presence of mesial step and Class III deciduous canine relationship were considered Class III. Class I molar relationships, including crowding, spacing, and rotations, were categorized as Class I malocclusions.

\section{Statistical analysis}

The rates of sagittal occlusal relationships were calculated for the study groups in different dentition stages. The statistical significance of malocclusion types in dentition stages was evaluated by Chi-square and Fischer's exact tests. Statistical analysis was performed with the Statistical Package for the Social Sciences, Version 15.0, for Windows (SPSS Inc., Chicago, USA), and $p<0.05$ was considered significant.

\section{Results}

Among all subjects, the distribution of sagittal occlusal relationships was as follows: $76.9 \%$ had Class I ( $\mathrm{n}=853), 11.4 \%$ had Class II $(\mathrm{n}=127)$, and $11.7 \%$ had Class III $(n=130)$ malocclusions. The distribution of subjects in the different dentition stages was: $14.6 \%(n=162)$ in the deciduous stage, $32.5 \%(n=361)$ in the early mixed stage, $24.0 \%(n=266)$ in the late mixed stage, and $28.9 \%(n=321)$ in the permanent dentition stage (Figure 1). The distribution of sagittal occlusal relationships by gender was as 


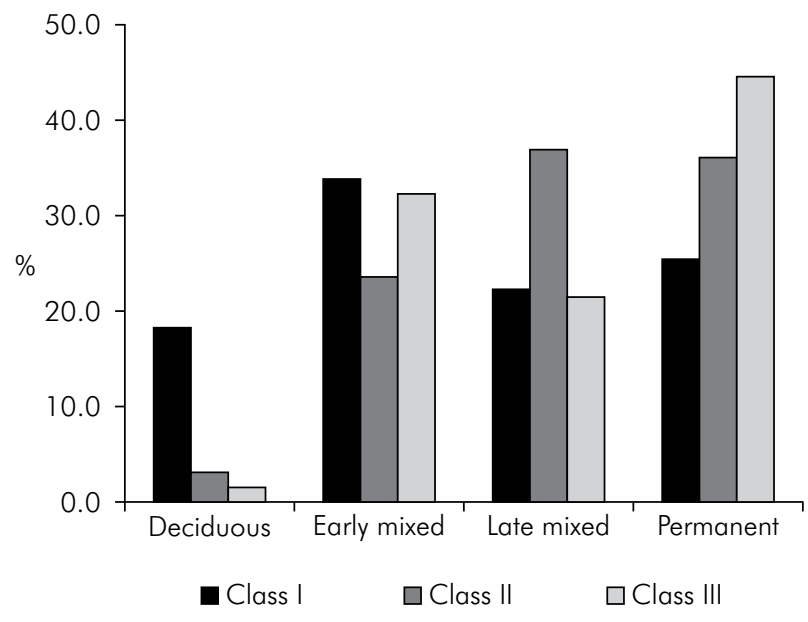

Figure 1. Distribution of sagittal occlusal relationships in subjects of each dentition stage.

follows: Class I malocclusion, $75.9 \%$ female $(n=426)$, $77.8 \%$ male $(\mathrm{n}=427)$; Class II malocclusion, $12.1 \%$ female $(\mathrm{n}=68), 10.7 \%$ male $(\mathrm{n}=59) ;$ Class III malocclusion, $12 \%$ female $(n=67), 11.4 \%$ male $(n=63)$ (Figure 2). There were no statistically significant differences between genders with regard to malocclusion class (Table 1).

As shown in Table 2, the distribution of sagittal occlusal relationships among the four stages of dentition was as follows: Deciduous dentition, Class I 96.3\%, Class II 2.5\%, Class III 1.2\%; early mixed dentition, Class I 80.1\%, Class II 8.3\%, Class III 11.6\%; late mixed dentition, Class I $71.8 \%$, Class II $17.7 \%$,

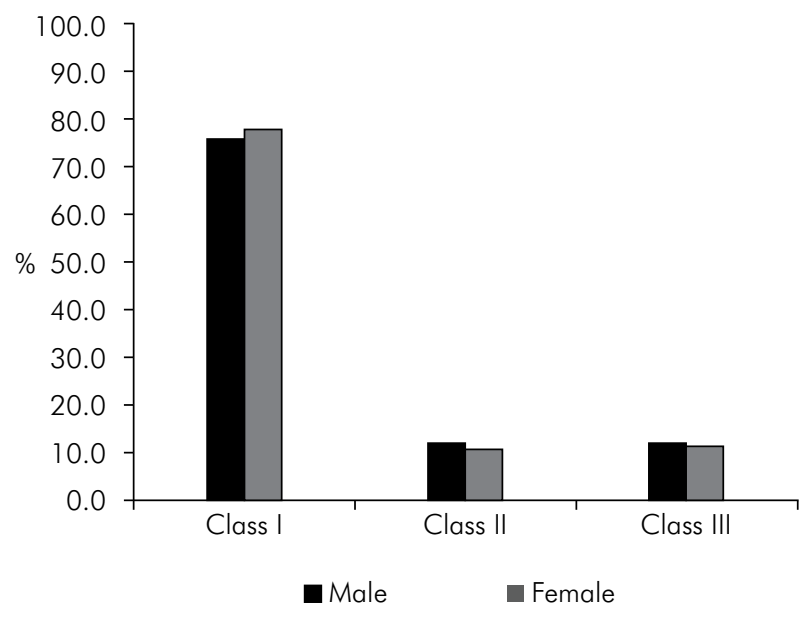

Figure 2. Distribution of sagittal occlusal relationships in subjects by gender.
Class III 10.5\%; permanent dentition, Class I 67.6\%, Class II 14.3\%, Class III 18.1\%.

Intergroup differences were found to be significant, and therefore pair-wise comparisons were performed.

\section{Comparison of sagittal occlusal relationships (Class I, II, and III) in relation to dentition stage}

Class II malocclusion was significantly more common in the early mixed $(p<0.01)$, late mixed $(p<0.001)$, and permanent $(p<0.001)$ dentition stages than in the deciduous stage. Class II malocclusion was significantly more common in the late mixed $(p<0.001)$ and permanent $(p<0.01)$ dentition stages than in the early mixed stage. Class III malocclusion was significantly more common in the early mixed, late mixed, and permanent dentition stages than the deciduous stage $(p<0.001)$, and Class III malocclusion was also significantly more common in the permanent dentition stage than in the early mixed and late mixed stages $(p<0.05)$.

\section{Discussion}

Angle's classification system is a reliable and repeatable method to define sagittal discrepancies that minimizes subjectivity. ${ }^{9}$ However, the distribution of Angle classes has been reported to vary for different ethnic groups. ${ }^{4,5,6,8,13,14,15}$ In this study, the sample set reflects the greater Turkish population because Ankara is the capital city located in the central part of Turkey, where individuals from every province of Turkey come to receive health care. Although several studies have classified malocclusions by chronological age, ${ }^{13,16}$ malocclusions appear to be more influenced by development of dentition than by chronological age. Permanent teeth have been found to emerge

Table 1. Distribution of sagittal occlusal relationships in subjects by gender.

\begin{tabular}{lccccc}
\hline & \multicolumn{2}{c}{ Female } & \multicolumn{2}{c}{ Male } & \multirow{2}{*}{$\mathrm{p}$} \\
\cline { 2 - 5 } & $\mathrm{n}$ & $\%$ & $\mathrm{n}$ & $\%$ & \\
\hline Class I & 426 & 75.9 & 427 & 77.8 & \\
Class II & 68 & 12.1 & 59 & 10.7 & 0.729 (NS) \\
Class III & 67 & 11.9 & 63 & 11.5 & \\
Total & 561 & 100.0 & 549 & 100.0 & \\
\hline
\end{tabular}

$\mathrm{n}$ : Number of subjects (n); \%: Percentage; NS: Non significant; $\chi^{2}=0.632$ 
Table 2. Distribution of sagittal occlusal relationships in subjects in each dentition stage.

\begin{tabular}{lccccccccc} 
& \multicolumn{2}{c}{ Deciduous $(\mathrm{n}=162)$} & \multicolumn{2}{c}{ Early Mixed $(\mathrm{n}=361)$} & \multicolumn{2}{c}{ Late Mixed $(\mathrm{n}=266)$} & \multicolumn{2}{c}{ Permanent $(\mathrm{n}=321)$} \\
\cline { 2 - 6 } & $\mathrm{n}$ & $\%$ & $\mathrm{n}$ & $\%$ & $\mathrm{n}$ & $\%$ & $\mathrm{n}$ & $\%$ \\
\hline Class I & 156 & 96.3 & 289 & 80.1 & 191 & 71.8 & 217 & 67.6 \\
Class II & 4 & 2.5 & 30 & 8.3 & 47 & 17.7 & 46 & 14.3 & $*$ \\
Class III & 2 & 1.2 & 42 & 11.6 & 28 & 10.5 & 58 & 18.1 & 100.0 \\
Total & 162 & 100.0 & 361 & 100.0 & 266 & 100.0 & 321 & 100
\end{tabular}

n: Number of subjects; \%: Percentage; ${ }^{*} p<0.05 ; x^{2}=65.339$

into the oral cavity earlier in African and AfricanAmerican children than in Caucasians. ${ }^{17}$ Therefore, determining the distribution of malocclusions in different dentition stages is more reliable than using chronological age as a reference. ${ }^{5}$

Although several studies have assessed sagittal occlusal relationships in one dentition stage or in an age range including multiple dentition stages, $3,5,6,8,13,14$ only two studies ${ }^{5,6}$ have assessed the prevalence of malocclusions in different dentition stages, specifically in Amerindian, Tanzanian Bantu, and Finnish subjects. Our present study is the first to compare the prevalence of sagittal occlusal relationships in different dentition stages in a Turkish population.

The most prevalent malocclusion type in this population was Class I in all dentition stages. This finding is in accordance with other reports for Turkish subjects. ${ }^{13,18}$ In contrast, Uslu et al. ${ }^{19}$ reported that Class II malocclusions are the most common (41.8\%) in 900 Turkish subjects with permanent dentition. The mean prevalence of Class I malocclusion (76.9\%) in our study was higher than in some other ${ }^{13,19}$ studies and showed a decreasing trend towards the permanent dentition. Among Tanzanian and Finnish individuals, the prevalence of neutral occlusion also tends to decrease from primary to mixed dentition. ${ }^{6}$

Class II malocclusion was observed to be the least prevalent malocclusion type in the deciduous dentition. The prevalence of Class II malocclusion showed a significant increasing trend towards the late mixed dentition stage, and then slightly decreased in the permanent dentition stage. This finding is consistent with the results of Thilander et al. ${ }^{5}$ showing that Turkish subjects have a lower frequency of Class II malocclusions than Iranian, ${ }^{16}$ Finnish, ${ }_{15}^{15}$ Danish, ${ }^{14}$ and Asian subjects. ${ }^{3}$ Class III malocclusion was observed to be the least frequent malocclusion type in the deciduous dentition stage, and the prevalence increased towards the permanent dentition stage. This result is in agreement with Thilander et al.,${ }^{5}$ but in contrast with Kapur et al., ${ }^{20}$ who reported a higher frequency of Class III malocclusion in younger children compared to older children with more erupted permanent teeth owing to the forward functional shift of the mandible.

The mean prevalence of Class III malocclusion $(11.7 \%)$ in our study of the Turkish population was higher than in Danish, ${ }^{14}$ Finnish, ${ }^{15}$ Iranian, ${ }^{16}$ Tanzanian, ${ }^{21}$ German, ${ }^{22}$ and Swedish ${ }^{23}$ populations but lower than in a Chinese population (49.1\%). ${ }^{8}$ The high prevalence of Class III malocclusion in Chinese might be due to differences in ethnicity. The prevalence of Class III malocclusion observed in a previous study of Turkish subjects was higher than in our study. ${ }^{13,18}$

Table 3 shows the rates of the three malocclusion classes in different populations reported in various studies. ${ }^{2,3,4,5,6,7,8,13,14,15,16,18,19,21,24}$ It is notable that prevalence rates varied even within Turkish populations of the same origin. Differences between our results and those of other studies are most likely due to differences in the selection of subjects. Our subjects were randomly chosen from patients referred to the Department of Dentomaxillofacial Radiology of Gazi University, whereas the subjects examined in the other studies were selected from patients referred directly to Orthodontic departments of other universities. ${ }^{13,18}$ Because Class III malocclusion produces distinct facial and dental features, subjects with this type of malocclusion are generally referred directly to orthodontic treatment, and this may account for the higher rates of Class III malocclusions in the other studies. Another factor that may have contributed to the variation in results is differences in the chronological ages and dentition stages of the subjects. 
Table 3. Prevalence (percent) of malocclusion in children and adolescents in different ethnic groups.

\begin{tabular}{|c|c|c|c|c|c|c|}
\hline \multirow{2}{*}{ Authors } & \multirow{2}{*}{ Population } & \multicolumn{2}{|c|}{ Subjects } & \multirow{2}{*}{$\begin{array}{c}\text { Class I } \\
\%\end{array}$} & \multirow{2}{*}{$\begin{array}{c}\text { Class II } \\
\%\end{array}$} & \multirow{2}{*}{$\begin{array}{c}\text { Class III } \\
\%\end{array}$} \\
\hline & & $\mathrm{n}$ & Age (years) & & & \\
\hline Helm S. (1968) & Danish & 1,700 & $9-18$ & 72.0 & 24.0 & 4.0 \\
\hline Yang (1990) & Chinese & 3,305 & $12-18$ & 35.9 & 14.9 & 49.1 \\
\hline Tod et al. (1997) & Australian & 216 & $18-64$ & 67.1 & 28.7 & 4.2 \\
\hline Thilander et al. (2001) & Bogotanian & 4,724 & $5-17$ & 75.5 & 20.8 & 3.7 \\
\hline Keski-Nisula et al. (2003) & Finnish & 972 & $4.0-7.8$ & 46.1 & 52.4 & 1.5 \\
\hline Sayin and Turkkahraman (2004) & Turkish & 1,356 & $10.4-16.7$ & 64.0 & 24.0 & 12.0 \\
\hline Mugonzibwa et al. (2004) & Tanzanian & 869 & $3.5-16$ & 26.3 & 50.2 & 23.5 \\
\hline Onyeaso et al. (2004) & Nigerian & 636 & $12-17$ & 74.0 & 14.0 & 12.0 \\
\hline Demir et al. (2005) & Turkish & 716 & $10-19$ & 76.0 & 20.3 & 3.7 \\
\hline Soh et al. (2005) & Chinese-Malay-Indian & 339 & $17-22$ & 53.1 & 25.1 & 21.2 \\
\hline Gabris et al. (2006) & Hungarian & 483 & $16-18$ & 52.8 & 39.1 & 8.1 \\
\hline Josefsson et al. (2007) & Asian & 64 & $12-13$ & 54.6 & 36.2 & 9.2 \\
\hline Josefsson et al. (2007) & Eastern European & 27 & $12-13$ & 42.2 & 46.9 & 10.9 \\
\hline Josefsson et al. (2007) & Swedish & 124 & $12-13$ & 47.0 & 48.8 & 4.2 \\
\hline Mtaya et al. (2009) & Tanzanian & 1,601 & $12-14$ & 93.6 & 4.4 & 2.0 \\
\hline Borzabadi-Farahani et al. (2009) & Iranian & 502 & $11-14$ & 41.8 & 27.5 & 7.8 \\
\hline Uslu et al. (2009) & Turkish & 900 & $12.9-22.1$ & 39.8 & 41.8 & 18.4 \\
\hline
\end{tabular}

n: Number of subjects; \%: Percentage

We found no significant differences in the prevalence of sagittal occlusal relationships between male and female subjects in the present study, consistent with several other studies. ${ }^{16,21,25,26}$ Contrary to the present results, Wood ${ }^{27}$ found a higher rate of Class I malocclusion in female subjects than in male subjects, and Onyeaso et al. ${ }^{24}$ reported higher rates of Class II and III malocclusion in male subjects than in female subjects.

\section{References}

1. Rudan I, Campbell H, Rudan P. Genetic epidemiological studies of eastern Adriatic Island isolates, Crotia: objective and strategies. Coll Antropol. 1999 Dec;23(2):531-46.

2. Soh J, Sandham A, Chan YH. Occlusal status in Asian male adults: prevalence and ethnic variation. Angle Orthod. 2005 Sep;75(5):814-20.

3. Josefsson E, Bjerklin K, Lindsten R. Malocclusion frequency in Swedish and immigrant adolescents--influence of origin on orthodontic treatment need. Eur J Orthod. 2007 Feb;29(1):79-87.

4. Gábris K, Márton S, Madléna M. Prevalence of malocclusions in Hungarian adolescents. Eur J Orthod. 2006 Oct;28(5):467-70.

5. Thilander B, Pena L, Infante C, Parada SS, de Mayorga C. Prevalence of malocclusion and orthodontic treatment

\section{Conclusion}

Class I malocclusion was the most common class in this Turkish population in all dentition stages.

The Class I malocclusion rate decreased from deciduous dentition towards permanent dentition, whereas the prevalence of Class II and Class III malocclusions increased significantly from deciduous to late mixed dentition. need in children and adolescents in Bogota, Colombia. An epidemiological study related to different stages of dental development. Eur J Orthod. 2001 Apr;23(2):153-67.

6. Mugonzibwa EA, Eskeli R, Kuijpers-Jagtman AM, Laine-Alava MT, van't Hof MA. Occlusal characteristics during different emergence stages of the permanent dentition in Tanzanian Bantu and finnish children. Eur J Orthod. 2004 Jun;26(3):251-60.

7. Tod MA, Taverne AA. Prevalence of malocclusion traits in an Australian adult population. Aust Orthod J. 1997 Oct;15(1):16-22.

8. Yang WS. The study on the orthodontic patients who visited department of orthodontics, Seoul National University Hospital (abstract). Taehan Chikkwa Uisa Hyophoe Chi. 1990 Sep;28(9):811-21. Korean. 
9. Silva RG, Kang DS. Prevalence of malocclusion among Latino adolescents. Am J Orthod Dentofacial Orthop. 2001 Mar;119(3):313-5.

10. Angle E. Classification of malocclusion. Dental Cosmos 1899;41(2):248-64.

11. Proffit WR, Fields HW, Sarver DM. Contemporary Orthodontics. 5th ed. St. Louis: Mosby Elsevier; 2013.

12. Bishara SE, Hoppens BJ, Jakobsen JR, Kohout FJ. Changes in the molar relationship between the deciduous and permanent dentitions: a longitudinal study. Am J Orthod Dentofacial Orthop. 1988 Jan;93(1):19-28.

13. Sayin MO, Türkkahraman H. Malocclusion and crowding in an orthodontically referred Turkish population. Angle Orthod. 2004 Oct;74(5):635-9.

14. Helm S. Malocclusion in Danish children with adolescent dentition: an epidemiologic study. Am J Orthod. 1968 May;54(5):352-66.

15. Keski-Nisula K, Lehto R, Lusa V, Keski-Nisula L, Varrela $\mathrm{J}$. Occurence of malocclusion and need of orthodontic treatment in early mixed dentition. Am J Orthod Dentofacial Orthop. 2003 Dec;124(6):631-8.

16. Borzabadi-Farahani A, Borzabadi-Farahani A, Eslamipour F. Malocclusion and occlusal traits in an urban Iranian population. An epidemiological study of 11- to 14-year-old children. Eur J Orthod. 2009 Oct;31(5):477-84.

17. Lavelle CLB. The timing of tooth emergence in four population samples. J Dent. 1976 Sep;4(5):231-6.

18. Demir A, Uysal T, Basciftci FA, Guray E. The association of occlusal factors with masticatory muscle tenderness in 10- to 19-year old Turkish subjects. Angle Orthod. 2005 Jan;75(1):40-6.
19. Uslu O, Akcam MO, Evirgen S, Cebeci I. Prevalence of dental anomalies in various malocclusions. Am J Orthod Dentofacial Orthop. 2009 Mar;135(3):328-35.

20. Kapur A, Chawla HS, Utreja A, Goyal A. Early class III occlusal tendency in children and its selective management. J Indian Soc Pedod Prev Dent. 2008 Sep;26(3):107-13.

21. Mtaya M, Brudvik P, Astrøm AN. Prevalence of malocclusion and its relationship with socio-demographic factors, dental caries, and oral hygiene in 12- to 14-year-old Tanzanian schoolchildren. Eur J Orthod. 2009 Oct;31(5):467-76.

22. Lux CJ, Dücker B, Pritsch M, Komposch G, Niekusch U. Occlusal status and prevalence of occlusal malocclusion traits among 9-year-old schoolchildren. Eur J Orthod. 2009 Jun;31(3):294-9.

23. Dimberg L, Lennartsson B, Söderfeldt B, Bondemark L. Malocclusions in children at 3 and 7 years of age: a longitudinal study. Eur J Orthod. 2013 Feb;35(1):131-7.

24. Onyeaso CO, Aderinokun GA, Arowojolu MO. The pattern of malocclusion among orthodontic patients seen in Dental Centre, University College Hospital, Ibadan, Nigeria. Afr J Med Med Sci. 2002 Sep;31(3):207-11.

25. Celikoglu M, Akpinar S, Yavuz I. The pattern of malocclusion in a sample of orthodontic patients from Turkey. Med Oral Patol Oral Cir Bucal. 2010 Sep 1;15(5):e791-6.

26. Shalish M, Gal A, Brin I, Zini A, Ben-Bassat Y. Prevalence of dental features that indicate a need for early orthodontic treatment. Eur J Orthod. 2013 Aug;35(4):454-9.

27. Wood BF. Malocclusion in the modern Alaskan Eskimo. Am J Orthod. 1971 Oct;60(4):344-54. 